\title{
A Pilot Study of Verbal Fluency in the Zulu Speaking Population with Preliminary Application to Traumatic Brain Injury
}

\author{
Terri-Leigh Sperinck and Janet de Picciotto \\ Department of Speech Pathology and Audiology \\ University of the Witwatersrand
}

\begin{abstract}
This study investigated the semantic verbal fluency (VF) abilities of non-neurologically impaired (NNI) Zulu speaking subjects in order to obtain normative data for this population. The data were analysed in terms of the total number of words generated in one minute, the number of words generated over four fifteen-second time periods and the strategies employed. Where possible, these results were compared to performance of South African English speaking NNI subjects. The responses of three traumatically brain injured (TBI) Zulu speaking subjects on VF tasks were obtained and compared to the NNI subjects. The NNI subjects performed significantly poorer than the current norms and poorer than the South African English speaking population. The TBI subjects generated fewer words than the NNI subjects. The strategies used by the TBI subjects were similar in type but were less efficiently used than the Zulu speaking NNI subjects. The results of this study are particularly relevant to the clinical role of speech pathologists in the multicultural and multilingual population of South Africa.
\end{abstract}

\section{OPSOMMING}

Hierdie studie is 'n ondersoek na die vermoë van nie-neurologies-gestremde Zoeloesprekers om woorde te herroep en produseer na aanleiding van semantiese hategorieë. Die doel van die studie was om normatiewe data te verkry vir hierdie groep sprekers. Die totale aantal woorde in een minuut geproduseer; die aantal woorde wat oor vier vyftien-sekonde periodes geproduseer is; en die strategieë wat deur die proefpersone gebruik is, is ontleed. Waar moontlik is dié resultate met die van Engelsprekende proefpesone vergelyk. Data is ook verkry van drie Zoeloesprekers met geslote hoofbeserings, en met die data van die nie-neurologies-gestremde groep vergelyk. Die nie-neurologies-gestremde Zoeloesprekers het swakker gevaar as die Engelsprekende groep sowel as die gepubliseerde norme. Die proefpersone met traumatiese hoofbeserings het minder woorde geproduseer as die nie-neurologies-gestremde groep, en alhoewel hulle dieselfde strategieë gebruik het as laasgenoemde, het hulle dit minder doeltreffend gebruik. Die resultate van hierdie studie is veral van belang binne die multikulturele, veeltalige Suid-Afrikaanse konteks.

KEY WORDS: verbal fluency, semantic verbal fluency, multicultural, multilingual !

Verbal fluency (VF) is a task commonly incorporated in the assessment batteries of Speech Pathologists and neuropsychologists in South Africa. In a population as culturally diverse as South Africa's, it is essential to recognise the need for normative data pertaining to assessment tasks conducted on the non-English speaking population in order to provide a basis against which to compare the performance of our clients. This study investigated VF abilities in a specific group from the Zulu speaking population of South Africa. In addition, a small sample of Zulu speaking Traumatic Brain Injured (TBI) subjects was investigated.

A discussion of $\mathrm{VF}$ and the provision of a rationale for the choice of Zulu speakers as the subject of investigation in this study, follows. Gruen, Frankle \& Schwartz (1990) define verbal fluency (VF) as "a language based task employed to measure word associate generation and divergence" (p.163). A review of the literature revealed a number of studies on VF in different population groups including the elderly; non-neurologically impaired; Alzheimer's Disease; Parkinson's Disease; Huntington's Disease; Dementia; Progressive Supranuclear Palsy and Head Injury populations (Adams, Reich \& Flowers, 1989; Bolla, Lindgren, Bonaccorsy \& Bleecker, 1990; Borkowski, Benton \& Spreen 1967; Cauthen, 1978; de Picciotto, 1997; Gruen et al., 1990; Hanley, Dewick, Davies, Playfer \& Turnbull, 1990). Numerous studies have shown that results of VF tasks may be influenced by age, sex and verbal intelligence (Bolla et al., 1990; Cauthen, 1978; Hanley et al., 1990).

The two VF tasks most utilised by researchers and clinicians are phonemic and semantic category tasks (Adams et al., 1989; Borkowski et al., 1967; dePicciotto, 1997; Hanley et al., 1990). In phonemic tasks, subjects are required to generate words that begin with a specific letter, whereas in semantic category tasks subjects are required to generate words that are part of a specific category. Phonemic VF is dependent on the "phonologically based word store" (Rosser 
\& Hodges, 1994 , p. 1389). Semantic VF requires the individuals to make an exploration of their conceptual knowledge followed by a lexical search according to semantic categories (Cardebat et al., 1996). The lexicon involved in semantic categories is stored in the semantic memory; the system of long term memory which contains general information about the world (Rosser \& Hodges, 1994).

Battig \& Montague (1969), as cited by Adams et al. (1989), found that the categories which are chosen for VF tasks have extensive effects on the scores of the subjects. There is a relationship between language and thought in the culture in which the language is spoken, therefore language and culture are reciprocal (Berry, Poortinga, Segall \& Dasen, 1992). Consequently, when choosing categories for VF tasks it is imperative to ensure that the categories are culturally appropriate. When obtaining normative data on an assessment tool for a population on which it was not originally normed, it is not enough to simply translate the test into the required language. As stated by Payne (1986), the roots of language are embedded in culture and as a result the two cannot be separated and thus it is necessary to adapt the test to the culture for which it is being normed.

When considering the applicability of the two types of VF tasks in the Zulu speaking population, the semantic category task of VF may be more appropriate than the phonemic tasks owing to the complexity of noun class marker and noun class agreement exhibited in Zulu (Suzman, 1996). Therefore a phonemic VF task was not felt to be appropriate because Zulu speakers make use of noun class prefixes when speaking, thus words would not simply be named but rather they would be said with their class prefixes. For example, "sock" in Zulu is "isokisi" however, the " $\mathrm{i}$ " which occurs at the beginning of the word is the noun class marker and not in fact the initial letter of the word.

VF tasks are performed over a 60-second time period. This performance can be further analysed in terms of four 15-second time periods. Adams et al. (1989) found that the non-neurologically impaired (NNI) subjects or subjects with Dementia of the Alzheimer Type (DAT) generated the most words during the initial fifteen-second time period, however, the DAT subjects exhibited a distinctive decrease in the number of responses in the ensuing time periods. Studies conducted by Cardebat et al. (1996) on right brain damaged subjects, and Crowe (1992) of TBI subjects, showed that there was a decrease in the number of words generated after the first 30 seconds.

When performing VF tasks the individual tends to use strategies. The ability to switch strategies when the series of associations runs out, as well as good organisational skills enhance performance in tasks of VF (Cauthen, 1978). There is currently limited data on strategy use in different populations.

A review of literature regarding tasks of VF revealed a paucity of research on VF using non-English speaking subjects. Benton \& Hamsher cited by Lezak (1995) established letter ranking norms in VF tasks in French, Germán, Italian and Spanish. There appears to be no published literature on VF research carried out in any African languages. Normative data for tasks of VF in African languages are important in the South African context because assessments currently being on non-English speaking clients are normed on English speakers.

South Africa is a country with vast ethnic diversity and a total population of 38 million. Mother tongue. Zulu speak- ers comprise $22,4 \%$ (6,4 million) of the total population. Within the Gauteng province, $18,4 \%$ of the people speak Zulu as their home language (Central Statistical Services, 1998). Zulu is the predominant African language spoken in South Africa. The most common language spoken Southern African townships is a hybrid of either Zulu or Xhosa (Maake, 1991). It can therefore be deduced that Zulu speakers form a large proportion of the Speech Pathologist's caseload.

In order to treat populations of various languages it is necessary to understand their languages and the way in which they organise their thoughts. Estes (1974) suggests that tasks of VF represent an ideal method of examining how subjects organise their thinking. Thus, normative data of Zulu speakers is imperative in order to establish baseline measures for the purpose not only of diagnosis but also for intervention. The performance of South African Zulu speakers as compared to South African English speakers on tasks of VF may provide valuable insight into cultural and linguistic differences in their approach to VF tasks.

There are numerous problems facing Speech Pathologists working in culturally and linguistically diverse populations. One of the most critical problems that the Speech Pathologist is faced with is "the absence of adequate assessment tools needed to provide valid and reliable evaluations" of linguistically and culturally disparate populations (Vaughn-Cooke, 1986, p. 23). The need for culturally appropriate tests is vital as the employment of invalid assessment tools has direct impact on the client's results which in turn have far reaching implications for diagnosis, intervention and outcome (Vaughn-Cooke, 1986; Watt, Penn \& Jones, 1996).

One population typically seen in Speech Pathologist's caseloads is that of TBI clients. The National Head Injury Foundation (NHIF) defines TBI as "an insult to the brain that is caused by an external force that may produce diminished or altered states of consciousness which results in impaired cognitive abilities or physical functioning" (Ponsford, 1995, p.1). Statistics show that 70\% of TBI's are caused by motor vehicle accidents (MVA) and that it is mostly men between the ages of 15-35 years that are affected (Gillis, 1996). Most of the men that are affected by TBI are from lower socio-economic classes who may have limited educational attainment (Ponsford, 1995; Watt, Penn \& Jones, 1996).

The mechanisms that occur as a result of TBI are complex and involve both focal and diffuse injuries (Gillis, 1996; Ponsford, 1995). Research has shown that there are cognitive, behavioural and language consequences of TBI (Borkowski, Benton \& Spreen, 1967; Gillis, 1996; Gruen et al., 1990; Ponsford, 1995; Schmitter-Edgecombe, 1996). The phenomenon of TBI is common worldwide although the pattern of causation differs from country to country. While the largest cause of TBI in South Africa is attributed to motor vehicle accidents the statistics show that TBI in the African populations is mostly as a result of violence (Brown \& Nel, 1991) and this etiology is adding to the statistics of TBI.

Verbal fluency abilities have been explored in the TBI population. TBI subjects generate fewer words on tasks of VF than NNI subjects (Gruen et al., 1990). The aforementioned result may be attributed to the disruption in organisational skills in TBI subjects, which are important requirements for tasks of VF (Gruen et al., 1990).

Furthermore, results of studies of TBI subjects indi- 
cate that while they make use of similar strategies as NNI subjects in VF tasks, the injury appears to influence the speed and effectiveness of the strategies that are employed (Gruen et al., 1990). Anatomically the frontal lobes appear to play a vital role in VF tasks and the well-documented vulnerability of the frontal lobes to injury in TBI may account for the above finding (Crowe, 1992; Rosser \& Hodges, 1994).

The purpose of this study was therefore to gather normative data on VF tasks for the Zulu speaking population and compare this performance to that of South.African English speakers in order to facilitate culturally and linguistically appropriate assessment, diagnosis and intervention. Furthermore, this study aimed to examine a sample of Zulu speaking TBI clients in order to obtain an indication of their performance in comparison to the NNI population.

\section{METHODOLOGY}

The research methodology followed the framework of de Picciotto (1997) with adaptations for the specific population of this study.

\section{AIMS}

This study aimed to explore VF performance in Zulu speaking subjects in order to gather normative data. The sub-aims were fourfold:

$>$ Firstly, to determine the number words generated by Zulu speaking NNI subjects and compare them to South African English speaking NNI subjects.

$>$ Secondly to determine the performance of $\mathrm{Zulu}$ speaking TBI subjects.

$>$ Thirdly to compare the results obtained by the Zulu speaking NNI and Zulu speaking TBI subjects.

$>$ Finally to describe any strategies used by the Zulu speaking NNI and Zulu speaking TBI subjects during VF tasks.

\section{RESEARCH DESIGN}

A structured survey design was used to achieve the aims of this research as the data are quantified and managed by means of descriptive statistics.

\section{SUBJECTS}

The subjects were required to meet the following criteria. All subjects had to be male Zulu speakers in the age range of 18-30 years with a minimum of 10 years of formal education. To control for the large diversity of educational standards within the South African geographical context (Hosking, 1992), subjects were required to have been raised and educated in the urban areas of Gauteng to achieve uniformity of the dialects of Zulu that the patients spoke and ensure that the patient's educational backgrounds were similar. In addition, the three TBI subjects had to be at least 3 months post head injury in order to allow for neurological stabilisation (Lezak, 1995).

The Zulu speaking NNI group was represented by forty subjects and three Zulu speaking TBI subjects were selected. The Zulu speaking NNI subjects ranged in age from $18-30$ years (mean age $=23.58$ years; $\mathrm{SD}=4.03$ years). Formal education of the NNI subjects ranged from 10-15 years (mean education $=10.15 ; \mathrm{SD}=0.99$ years). Owing to the small sample size of the Zulu speaking TBI subjects statistical inferences could not be made, however, their details are provided in Table 1.

\section{TESTING}

In order to ascertain performance of the Zulu speaking NNI subjects as well as Zulu speaking TBI subjects on tasks of semantic VF, three categories were chosen, namely: "animals"; "food" and "transport", as they are most commonly used by researchers in studies of VF (Gruen et al., 1990; Hanley et al., 1990). These three categories were the ones that were least likely to be affected by culture (Berry et al., 1992). The subjects were given a trial category of "clothes" before beginning the task. The procedure employed required that each subject generate as many words as possible over a one-minute time interval for each of the three categories. The categories were presented in the following order: "animals", "food" and "transport". The interpreter verbally requested the subjects to continue if they stopped before the full minute (Joannette et al., 1988). At no time during the task were the subjects provided with cues. A tape recorder was used to record the subjects' responses and a stopwatch was used to time each task.

The number of words generated in one minute for each category was totalled. The one- minute time interval was

TABLE 1: Description of Zulu speaking TBI subjects.

\begin{tabular}{|l|c|c|c|}
\hline & SUBJECT \# 1 & SUBJECT \# 2 & SUBJECT \# 3 \\
\hline AGE & 18 & 25 & 19 \\
\hline ETIOLOGY & assault & MVA & stab wound \\
\hline COMA & 1 week & unknown & unknown \\
\hline TIME SINCE INJURY & 6 months & 15 months & 18 months \\
\hline $\begin{array}{l}\text { EDUCATION LEVEL } \\
\text { PREMORBD }\end{array}$ & Std.8 & Std.8 & Std.8 \\
\hline $\begin{array}{l}\text { EMPLOYMENT STATUS } \\
\text { CURRENT }\end{array}$ & unemployed & storeman & Unemployed \\
\hline EMPLOYMENT STATU's & unemployed & unemployed & Unemployed \\
\hline
\end{tabular}


then divided into four time intervals of fifteen-seconds each. The number of words generated in each of the four fifteen-second time intervals were then summed for each category. The strategies used by the subjects were analysed in terms of type and efficiency. A strategy was presumed if a subject's response was related to the word immediately preceding it (Gruen et al., 1990).

Once the instructions for the semantic VF task had been translated they were piloted on a small group of Zulu speaking males. A number of alterations were made and these included a more explicit explanation of the 60-second time period for each category as well as clearer instructions not to make use of proper nouns.

Owing to the fact that all testing was conducted in Zulu, a translator was required to translate the instructions of the VF tasks into Zulu. The translator was chosen according to the criteria suggested by van Ede (1996), that is, he was required to be proficient in English and Zulu, in order to translate the instructions for the task into Zulu from English.

Once the material had been translated, the process of back translation was employed. This is a process whereby a second person, proficient in both languages, translates the material back into the original language. The second translator does not have any previous knowledge of the original material, thereby ensuring that he is not biased. Back translation is conducted to guard against any errors that the first translator may have made. These errors include grammatical structures, word complexity and overall resemblance of the meaning (van Ede, 1996).

The original translator was used as an interpreter because he was proficient in both English and Zulu and he had knowledge of the testing material. He was then instructed in the administration of the VF tasks and worked with the researcher in transcribing the responses.

\section{DATA ANALYSIS}

In order to address the main aim, normative data were depicted by tabulating the results of the 40 Zulu speaking NNI subjects. The means for the number of.words for each category were established as well as for each time period within each category. According to von Fraunhofer \& Murray (1976), the most common method of ascertaining 'normal' is to determine the mean. Standard deviation (SD), for the number of responses in each category and the number of responses for each time period, was then calculated. SD was used to determine how much the individual values deviated from the mean values. The percentage of SD to the mean was calculated to obtain an indication of the relative differences between the SD. This calculation was carried out for each category and for each time period of each category. These calculations were used to compare the results between the three categories and to compare the results of each of the four time periods within the three categories. The results were then depicted graphically in order to ascertain whether any patterns or trends were present.

The results of the Zulu speaking NNI subjects on the categories of "animals" and "transport" were compared to the results of South African English speaking NNI subjects (de Picciotto, 1997). The category "food" was not included in this comparison since it was not used in the study on South African English speakers.

The means for the number of responses for each cat- egory were tabulated into frequency distributions and then represented graphically in the form of a distribution curve. These graphs were plotted in order to ascertain whether there was a Gaussian (normal) distribution about the mean or whether there was a Poisson (skewed) distribution about the mean (von Fraunhofer \& Murray, 1976).

To address the second aim of the study the result of each Zulu speaking TBI subject was calculated and analysed descriptively. To address the third aim of the study the responses of the Zulu speaking TBI subjects were compared to those of the Zulu speaking NNI subjects. Percentile ranking was used for each of the Zulu speaking TBI subjects. This analysis provided information as to each Zulu speaking TBI subject's relative position in the normative sample (Anastasi, 1982).

Finally, the results of the Zulu speaking NNI subjects were examined to look for 'patterns' of strategies within the responses. Types of strategies that can be used are alphabetical or subordinate categories. However; these strategies may be language specific. When naming in the Zulu language all words begin with vowel such as 'i'; ' $u$ '; ' $a$ '. Thus to analyse the results in terms of the alphabet would not have been linguistically appropriate. Likewise; the use of subordinate categories can be subject to the influence of culture. For example the category of food may be analysed in terms of food groups (vegetable, fruits, starches, meat etc.); meals (breakfast, lunch \& supper); staple diet (the foods that are indigenous to the culture); and finally ceremonial foods (those foods that are eaten during important occasions). The subordinate categories used were analysed according to culture-specific organisation.

Where possible the responses were arranged into groups for each subject. These groupings by subject were analysed numerically and separated according to perceived 'use' or 'non-use' of subordinate categories. The mean number of words achieved by the two groups was calculated and compared to assess efficiency of the subordinate categories. 'Efficiency of applying a strategy' was defined as the comparative degree to which those subjects utilising a strategy generated a higher mean number of words than the subjects who did not use a strategy.

\section{RESULTS AND DISCUSSION}

\section{1}

Results are discussed according to each aim of the study.

\section{WORDS GENERATED BY ZULU SPEAKING NNI SUBJECTS IN TOTAL AND OVER FOUR FIFTEEN- SECOND TIME PERIODS.}

Table 2 depicts the results obtained on the VF tasks for the Zulu speaking NNI subjects.

The mean number of words generated for the categories "animals" and "food" was similar (means of 11.52 and 11.65 respectively) however, for the category of "transport", fewer words were generated (mean of 7.75). The results for the category of "transport" may be attributed to the fact that there are a limited number of possible responses for the category. When the standard deviation (SD) was calculated as a percentage of the mean for the total words, the results within each category were relatively similar across the groups of "animals", "food" and "transport" (27.51\%; $28.87 \%$ and $26.61 \%$ respectively). This result may imply that the word generation abilities that are being 
used are working consistently across all three categories.

Overall, the number of words generated by the Zulu speaking NNI subjects of this study is much lower than the normative data currently being used (Bayles \& Tomoeda, 1991; Bayles \& Tomoeda, 1993; Goodglass \& Kaplan, 1972). According to the normative data the norm for "animals" is 22.5 ( $\mathrm{SD}=6.8$ ) and for "transport" is 13.4 $(\mathrm{SD}=3.2)$. When compared with the mean for "animals" (11.53) and "transport" (7.78) obtained in this study, the large difference suggests that a test with linguistically appropriate norms would be more appropriate.

In addition when comparing the results of the Zulu speaking NNI subjects to that of South African English speaking NNI subjects obtained in a previous study (de Picciotto, 1997) there was a significant difference $(p<0.001)$ (Table 2). The Zulu speaking NNI subjects generated fewer words for the categories of "animals" than the South African English speaking NNI subjects (means of 11.53 \& 23.30 respectively). This inter-group difference was highly significant $(t=-17.23, p<0.001)$. The Zulu speaking NNI subjects generated fewer words for the categories of 'transport' than the South African English speaking NNI subjects (means of $11.65 \& 17.30$ respectively). This intergroup difference was highly significant $(\mathrm{t}=-17.93$, $\mathrm{p}<0.001)$. No comparison could be made for the category of "food", as this category was not used in the study of South African English speaking subjects.

The four fifteen-second time periods for each task were analysed. Across individual time periods, similar patterns were observed across all categories (Table 2 \& Figure 1 ).

The highest number of words was generated during the first time period across all categories. A decrease in the mean number of words generated over time was noted, as can be seen in Table 2. This decrease in the number of words occurred most notably between the first and second time period. The slopes of the three graphs displayed in Figure 1 are similar and it could imply a consistency across categories in the word generation ability of the subjects.

The time periods of the Zulu speaking NNI subjects were also compared to the time periods of the South African English speaking NNI subjects for "animals" and "transport" (Table 2). For the category "animals" all time periods differed significantly although time period 4 was only significant at $p<0.01$. For the category "transport" all time periods differed significantly.

The frequency distribution curves displayed in Figure 2 approximate a normal distribution for all three categories which can not be deduced purely from an analysis of the standard deviations. A normal distribution indicates that the population behaved as a coherent whole. This normal distribution implies that any decisions that are made based on this normative data should be valid consistently across the Zulu speaking population.

WORDS GENERATED BY TBI SUBJECTS IN TO. TAL AND OVER FOUR FIFTEEN-SECOND TIME PERIODS.

Three TBI subjects were used in order to obtain an initial indication of the performance of neurologically impaired cases that may be seen in the Speech Pathologists caseload. The results obtained from the VF tasks of the three TBI subjects are depicted in Table 3.

As can be seen from Table 3, a subject who performed

Table 2: Responses on each semantic verbal fluency task for Zulu speaking and South African English speaking NNI subjects $(\mathrm{df}=53)$

\begin{tabular}{|c|c|c|c|c|c|}
\hline$\therefore$ & $\begin{array}{c}\text { Mean of Zulu } \\
\text { speaking NNI } \\
\text { subjects }\end{array}$ & $\begin{array}{c}\text { Standard } \\
\text { Deviation (SD) } \\
\text { of Zulu } \\
\text { speaking NNI } \\
\text { subjects }\end{array}$ & $\begin{array}{l}\text { SD \% of } \\
\text { Mean }\end{array}$ & $\begin{array}{l}\text { Mean of South } \\
\text { African English } \\
\text { speaking NNI } \\
\text { subjects }\end{array}$ & $t$ values \\
\hline Animals 1 & 5.575 & 1.448 & 25.97 & 9.60 & $-2.87^{\text {th }}$ \\
\hline Animals 2 & 2.775 & 1.265 & 44.00 & 6.07 & $-4.32^{\text {kitin }}$ \\
\hline Animals 3 & 1.825 & 1.217 & 66.85 & 4.40 & $-3.65^{m i n}$ \\
\hline Animals 4 & 1.250 & 1.565 & $125.00^{\circ}$ & 3.27 & $-1.77^{n}:$ \\
\hline Total animals & 11.525 & 3.170 & 27.51 & 23.3 & $-17.23^{\text {wat }}$ \\
\hline Food 1 & 5.825 & 1.981 & 32.88 & & \\
\hline Food 2 & 2.825 & 1.299 & 45.98 & & \\
\hline Food 3 & 1.675 & 1.265 & 74.41 & & \\
\hline Food 4 & 1.100 & 1.257 & 114.27 & & \\
\hline Total food & 11.650 & 3.363 & 28.87 & & \\
\hline Transport 1 & 4.675 & 1207 & 25.80 & 8.33 & $-7.27^{\text {tat }}$ \\
\hline Transport 2 & 2.100 & 1.128 & 53.71 & 3.53 & $-3.78^{* * *}$ \\
\hline Transport 3 & 0.850 & 1.027 & 120.82 & 3.13 & $-4.89^{4 \text { tith }}$ \\
\hline Transport 4 & 0.150 & 0.427 & 93.30 & 2.40 & $-4.54^{\text {tit }}$ \\
\hline Total transport & 7.775 & 2.069 & 26.61 & 17.30 & $-17.93^{* *}$ \\
\hline
\end{tabular}

KEY: $1-4=$ first to fourth 15 -second time period

$$
\begin{aligned}
* \quad & =p<0.1 \\
& =p<0.001
\end{aligned}
$$


well on one category did not necessarily do so on the other categories. The subject who performed most consistently was subject \#3. The number of words generated by all three subjects for all categories were well below the current norms. The number of words generated for "animals" and "food" is greater than for "transport" except for subject number 1 . This may be attributed to the fact that "transport" is a more difficult category with a limited number of possible responses.

Ideally it would have been valuable to compare performance over four time periods of the TBI subjects to the performance of the Zulu speaking NNI subjects. However, given the small number of TBI subjects this comparison was not possible. Examination of the TBI responses show a trend for most words to be generated in the first time period although this trend was not consistent for example, subject number 2 and subject number 3 for the category of "food".

\section{COMPARISON OF VERBAL FLUENCY PERFORM- ANCE IN ZULU SPEAKING NNI \& TBI SUBJECTS}

Although no direct comparison between the two groups was possible, the results of this study are consistent with previous research on tasks of VF in TBI subjects (de Picciotto, 1997; Gruen et al., 1990).

TABLE 3: Responses on each semantic verbal fluency task for the three TBI subjects.

\begin{tabular}{|l|c|c|c|}
\hline & $\begin{array}{c}\text { TBI } \\
\text { subject \#1 }\end{array}$ & $\begin{array}{c}\text { TBI } \\
\text { subject \#2 }\end{array}$ & $\begin{array}{c}\text { TBI } \\
\text { subject \#3 }\end{array}$ \\
\hline animals 1 & 2 & 2 & 2 \\
\hline animals 2 & 2 & 1 & 0 \\
\hline animals 3 & 1 & 1 & 1 \\
\hline animals 4 & 2 & 0 & 1 \\
\hline total animals & 7 & 4 & 4 \\
\hline & & & \\
\hline food 1 & 3 & 4 & 0 \\
\hline food 2 & 0 & 1 & 0 \\
\hline food 3 & 1 & 3 & 1 \\
\hline food 4 & 0 & 0 & 3 \\
\hline total food & 4 & 8 & 4 \\
\hline & & & \\
\hline transport 1 & 2 & 2 & 2 \\
\hline transport 2 & 1 & 0 & 1 \\
\hline transport 3 & 1 & 0 & 0 \\
\hline transport4 & 1 & 0 & 0 \\
\hline total transport & 5 & 2 & 3 \\
\hline
\end{tabular}

KEY: $1-4$ = first to fourth 15 -second time period

TABLE 4: An example of strategy use in semantic tasks of verbal fluency by Zulu speaking NNI subject \# 20 for the categories "food" and "transport".

\begin{tabular}{|l|c|}
\hline \multicolumn{1}{|c|}{ Food } & Transport \\
\hline $\begin{array}{l}\text { - Staple : amazi, beans, pap, } \\
\text { cabbage, spinach, bread, } \\
\text { rice }\end{array}$ & $\begin{array}{c}\text { Daily: car, taxi, bus, train, } \\
\text { wagon, lorry, bicycle }\end{array}$ \\
- Ceremonial : heart, brain, \\
liver, tongue
\end{tabular}

The TBI subjects generated considerably fewer words than the NNI subjects. This pattern was also seen over the four time periods. Based solely on this descriptive analysis the TBI subjects are not performing as well as the NNI subjects. The performance of each TBI subject was so poor that their results did not reach the tenth percentile of the normative sample.

\section{STRATEGY USE OF ZULU SPEAKING NNI SUB- JECTS versus TBI SUBJECTS}

The strategies were analysed descriptively according to subordinate categories. For the category "animals" the Zulu speaking NNI subjects appeared to use the subordinate categories of "wild animals"; "farm animals" and "domestic animals". The subjects appeared to make use of the subordinate categories "staple diet" and "ceremonial food" for the category of "food", although some of the subjects also made use of the category of "fruit". For the category of "transport" the NNI subjects appeared to make use of the subordinate category of "daily transport". However, it should be noted that the above-mentioned strategies were all inferred, as the subjects were not required to describe each strategy.

The Zulu speaking NNI subjects made use of strategies that were different from the expected strategies. For the category of "transport", instead of using subordinate strategies of "land", "sea" \& "air" (de Picciotto, 1997), the subject's first choice of the subordinate category could be called "daily transport". The South African English speaking subjects appeared to make use of a wider range of more specific subordinate categories such as for "land": "animal driven", "two wheel", "four wheel" and "recreational equipment" - skateboard, rollerblades \& rollerskates (de Picciotto, 1997). The difference in subordinate categories used by the Zulu speaking NNI and the South African English speaking NNI subjects could be attributed to the different backgrounds and experiences of the two groups. The category of "food" in the Zulu speaking NNI subjects highlights this point in that they made use of subordinate categories of "staple food" and "ceremonial food" instead of possibly more expected subordinate categories of "fruit"; "vegetable"; "meat" and "starch". An example of this pattern can be seen in Table 4.

The TBI subjects tended to use similar subordinate categories to those used by the Zulu speaking NNI subjects. However, an analysis of the data indicated that the TBI subjects were not using the strategies as efficiently as the Zulu speaking NNI subjects. The TBI subjects generated fewer words in the subordinate categories than the Zulu speaking NNI subjects. An example of this pattern can be seen in Table 5 .

Owing to the limited number of words generated by the TBI subjects inferred strategies were difficult to identify. Once again it is necessary to re-iterate that owing to the small sample size inferences cannot be generalised to the broader TBI population.

\section{GENERAL DISCUSSION}

The TBI subjects tended to generate fewer words than the Zulu speaking NNI subjects, which is in agreement with the findings of Crowe (1992); de Picciotto (1997) and Gruen et al. (1990). As with the Zulu speaking NNI subjects, the TBI subjects generated the most words within 
the first time period and thereafter a decrease in the number of responses was observed. All three TBI subjects reported memory and attentional deficits as a result of their injury so perhaps the decrease in the number of responses may be attributed to these cognitive deficits (Schmitter-Edgecombe, 1996).

The results from the data of the Zulu speaking NNI subjects indicate a decrease in the number of responses across the four time periods, notably so between the first and the second time period. This finding concurs with Adams et al. (1989) who found that the most responses were generated by NNI subjects during the first time period.

The Zulu speaking NNI subjects appeared to have made use of subordinate categorisation as a strategy for word generation but the use of 'subcategories' varied. The majority of the subjects appeared to generate words in one category until they had exhausted their lexicon while the remaining subjects appeared to switch between 'sub-categories'. While the. TBI subjects appeared to have made use of the same subordinate categorical strategies as used by the Zulu speaking NNI subjects, the TBI subjects did not make use of them as efficiently as the Zulu speaking NNI subjects. This inefficiency of strategy use could be seen by the fewer words generated by the TBI subjects for each subordinate category. The same results were seen in a study conducted by Gruen et al. (1990). The results from the TBI subjects cannot be generalised to the larger TBI population owing to the small nature of the sample size.

\section{CONCLUSION}

Normative data were obtained with regard to the performance and use of strategies in Zulu speaking NNI subjects on semantic VF tasks. A further result of this study, that Zulu speaking TBI subjects perform more poorly than Zulu speaking NNI subjects, concurred with previous studies (Borkowski et al., 1967; Crowe, 1992; de Picciotto, 1997; Gruen et al., 1990). A pattern of performance over four fifteen-second time periods was observed for both groups with the TBI subjects performing more poorly than the Zulu speaking NNI group. While the TBI subjects appeared to use similar strategies to the Zulu speaking NNI subjects when generating words, the TBI subjects did not use the strategies as efficiently. Finally, this study provided an indication of the performance of Zulu speaking TBI individuals.

From the results obtained a number of clinical and theoretical implications can be drawn. The use of tests that have been appropriately normed can play a crucial role in the correct identification of a patient's strengths and weaknesses that may in turn affect the therapy process. Using assessment tools on patients for whom the tools have not been normed, may not provide the clinician with a true reflection of the patients' ability.

While it may appear that tasks of VF are not culturally biased, the choice of the semantic category may not be equivalent across all population groups. The use of VF tasks may be of great benefit during diagnosis, assessment and intervention with different population groups on the

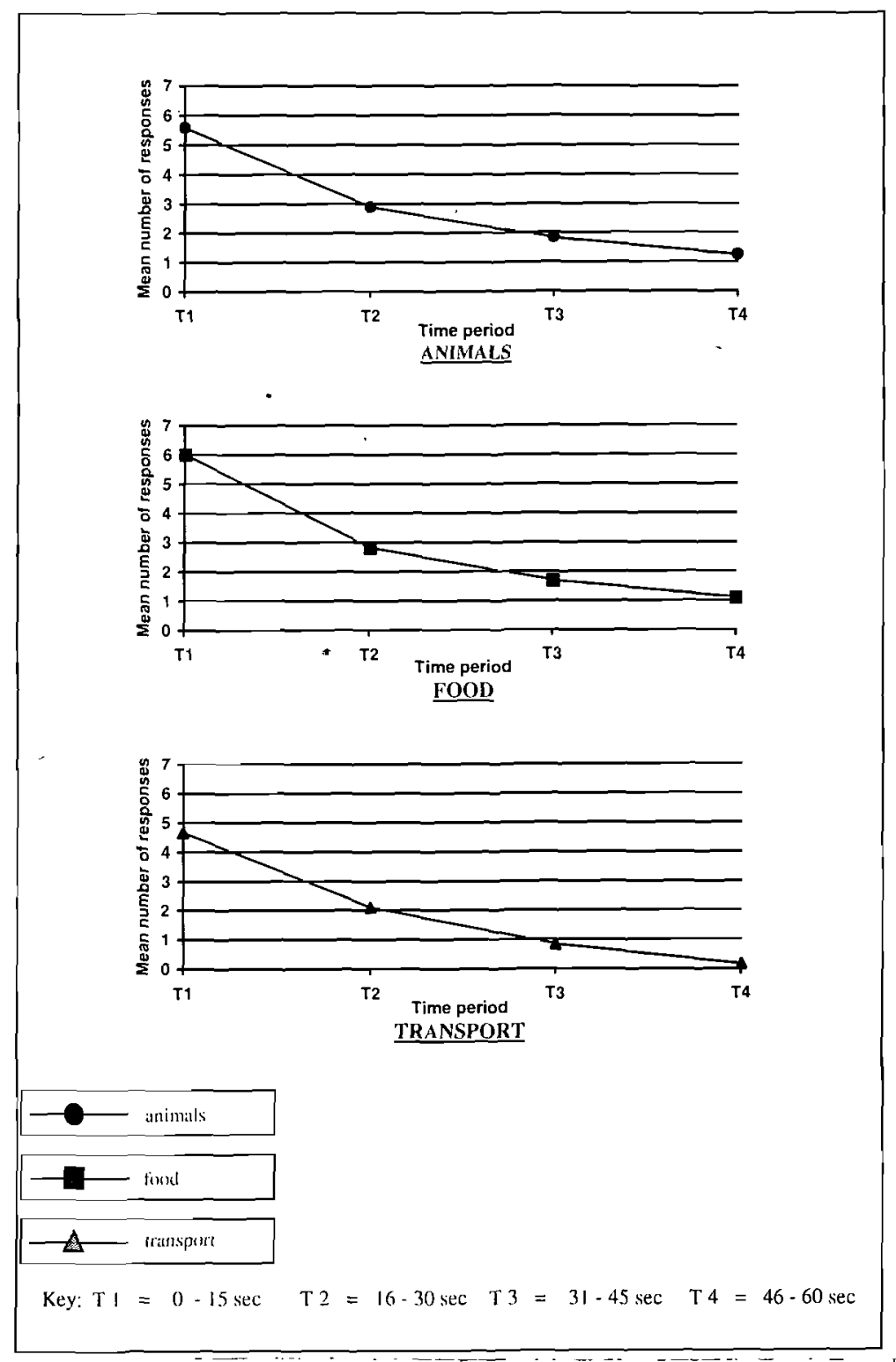

FIGURE 1: Mean number of responses of Zulu speaking NNI subjects plotted as a function of VF task and time period.

TABLE 5: An example of strategy use in semantic tasks of verbal fluency by TBI and Zulu speaking NNI subjects.

\begin{tabular}{|c|c|c|}
\hline Strategy & TBI subject \# 2 & NNI subject \# 21 \\
\hline $\begin{array}{l}\text { Organise words into subordinate } \\
\text { categories }\end{array}$ & $\begin{array}{l}\text { - Domestic: dog / cat } \\
\text { - Farm: cow } \\
\text { - Wild: baboon } \\
\text { - Domestic: dog / cat }\end{array}$ & $\begin{array}{l}\text { - Farm: cow / goat / chicken / sheep } \\
\text { - Wild: lion / leopard/snake / crocodile } \\
\text { / elephant / porcupine/ } \\
\text { hare / squirrel / jackal / owl / buffalo }\end{array}$ \\
\hline
\end{tabular}


proviso that the categories assessed are culturally and linguistically appropriate.

If TBI individuals are using the same word generation strategies as the NNI individuals, the clinician may be better able to assist the TBI individual in maximising the use of compensatory strategies. It is important to bear culture in mind when teaching compensatory strategies, as different cultures may make use of different strategies. As clinicians we have to be sensitive to these subtle differences.

A number of research implications emerged from this study. While the results obtained in this study provide initial normative data for the Zulu speaking population it is essential to replicate this study in order to gather additional support for these findings.

This study has highlighted that VF tasks are not free from cultural bias in terms of the semantic categories that may be utilised. Thus it is important to determine which semantic categories are most culturally appropriate for

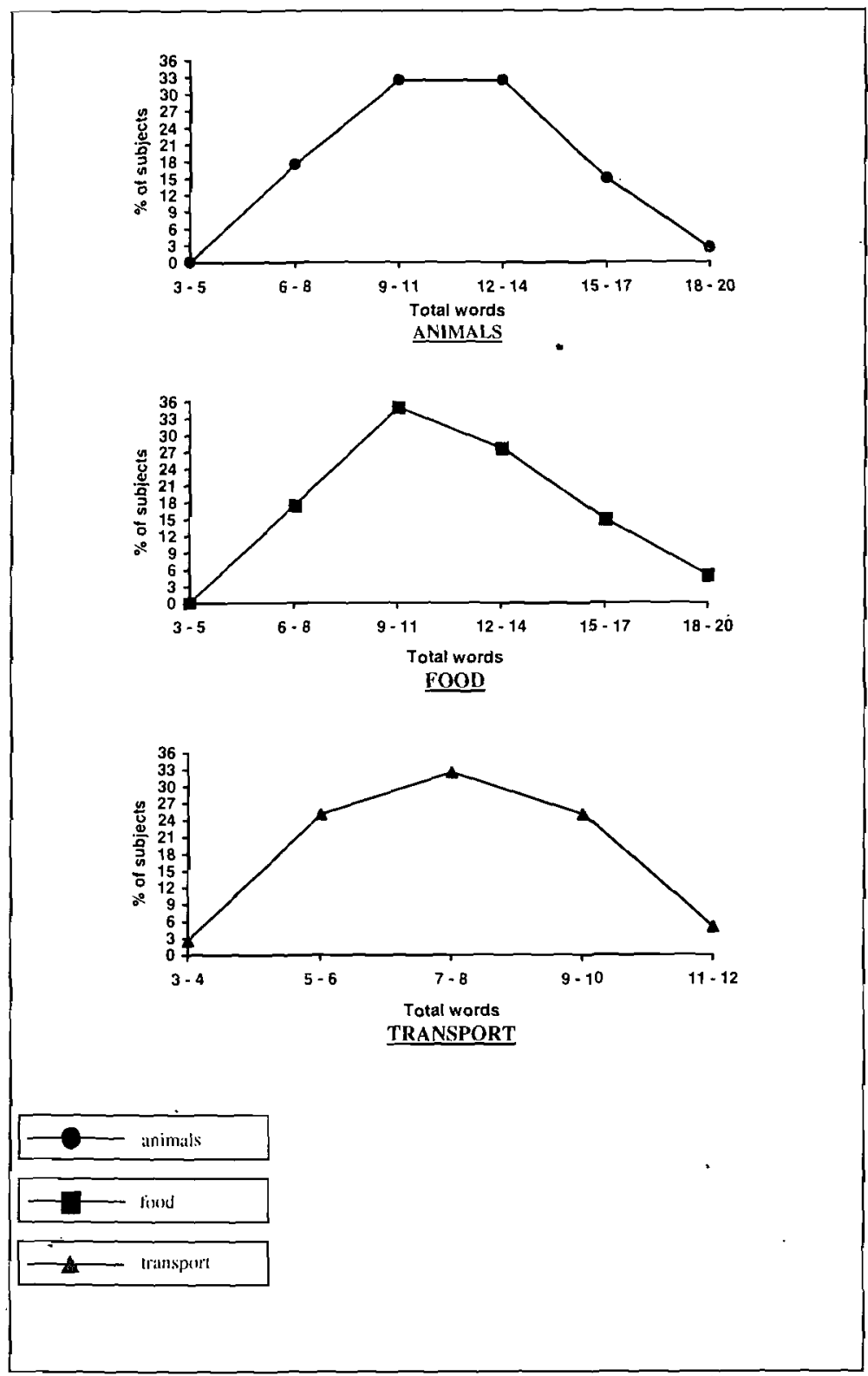

FIGURE 2: Percentage of Zulu speaking NNI subjects plotted as a function of VF task and total number of words. specific population groups.

A study making use of a large group of TBI subjects is necessary owing to the fact that the results obtained from this study cannot be generalised to the broader TBI population because of the nature of the sample size. Further investigation into this population group would be imperative to the clinician owing to the ever-increasing number of TBI individuals seen on our caseload.

Given the discrepancy between the normative group in this study and the norms currently being used, the need for research in the African languages is essential if we, as clinicians, are to provide all our clients with appropriate assessment and intervention.

In conclusion, South Africa, with its multilingual and multicultural population, needs normative data for assessment materials for language groups other than English. This study presents initial normative data for semantic VF tasks for the Zulu speaking population. As clinicians and researchers in South Africa, we need to be aware of the effects of tests and therapy methods which are not always appropriate for the different cultures and languages with whom we are required to work. If these tests can be administered in the client's language and compared with appropriate normative data, the clinician may obtain a clearer understanding of their clients' true abilities and thus better assist them in the therapy process.

\section{REFERENCES}

Adams, M.L., Reich, A.R., \& Flowers, C.R. (1989). Verbal fluency characteristics of normal and aphasic speakers. Journal of Speech and Hearing Research, $32,871: 879$.

Anastasi, A. (1982). Psychological testing (5 $5^{\text {th }}$ ed.). New York: Macmillan.

Bayles, K.A., \& Tomoeda, C.K. (1991). Arizona Battery for Communication Disorders of Dementia. Tucson: Canyonlands.

Bayles, K.A., \& Tomoeda, C.K. (1993). Scoring and interpretation of $A B C D: A$ reference guide. Tucson:Canyonlands.

Berry, J.W., Poortinga, Y.H., Segall, M.H. \& Dasen, P.R. (1992). Cross-cultural psychology: Research application. Cambridge: Cambridge University Press.

Bolla, K., Lindgren, K., Bonaccorsy, C., \& Bleecker, M. (1990). Predictors of verbal fluency (FAS) in the heal thy elderly. Journal of Clinical Psychology, 46 (5), $623-628$

Borkowski, J.G., Benton, A.L., \& Spreen, O. (1967). Word fluency and brain damage. Neuropsychologia, 5, 135140

Brown, D.S. \& Nel, V. (1991). Epidemiology of traumatic brain injury in Johannesburg-I. Methodological issues in a developing country context. Social Science and Medicine, 33 (3), 283-287.

Brown, D.S. \& Nel, V. (1991). Epidemiology of traumatic brain injury in Johannesburg-II. Morbidity, mortality and etiology. Social Science and Medicine, 33 (3), 289296.

Cardebat, D., Demonet, J.F., Viallard, G., Faure, S., Puel, M., \& Celsis, P. (1996). Brain function profiles in formal and semantic fluency tasks: ASPECT study in normals. Brain and Language, 52, 305-313.

Cauthen, N.R. (1978). Verbal fluency: normative data Journal of Clinical Psychology, 34 (1), 126-129.

Central Statistical Services (1998). Census. October 1996. South Africa.

Crowe, S.F. (1992). Dissociation of two frontal lobe syndromes by a test of verbal fluency. Journal of Clinical and Experimental Neuropsychology, 14 (2), 327-339.

de Picciotto, J. (1997). Verbal fluency: An indicator of mild 
traumatic brain injury. M.A. Speech Pathology, University of the Witwatersrand, Johannesburg

Estes, W.K. (1974). Learning theory and intelligence. American Psychologist, 26, 740-749.

Gillis, R. (1996). Traumatic brain injury: rehabilitation for speechlanguage pathologists. Boston: Butterworth-Heinemann.

Goodglass, H., \& Kaplan, E.F. (1972). Boston Diagnostic Aphasia Examination. Philadelphia: Lea \& Febiger.

Gruen, A.; Frankle, B., \& Schwartz, R. (1990). Word fluency generation skills of head-injured patients in an acute trauma center. Journal of Communication Disorders, 23, 163-170.

Hanley, J., Dewick, H., Davies, A.P., Playfer, J., \& Turnbull, C. (1990). Verbal fluency in Parkinson's disease. Neuropsychologia, 28, 737-741.

Hedge, M. (1987). Clinical research in communication disorders Principles \& strategies. Boston: Little Brown \& Company.

Hosking, S.G. (1992). The paradox of black pupil enrolment growth rates in South African schools. Development Southern Africa, 9 (3), 317-328

Joannette, Y., Goulet, P., \& Le Dorze, G. (1988). Impaired word naming in right-brain damaged right handers: Error types and time course analyses. Brain and Language, 34, 54-64

Lezak, M. (1995). Neuropsychological assessment. New York: Oxford University Press.

Maake, N.P. (1991). Language and politics in South Africa. English Studies, 34 (2), 55-64.

Payne, K.T. (1986). Cultural and linguistic groups in the United States. In O. Talyor (Ed.). Nature of communication disorders in culturally and linguistically diverse populations. California: College-Hill Press.
Ponsford, J. (1995). Mechanisms, recovery, and sequelae of traumatic brain injury. In J. Ponsford, S. Sloan \& P. Snow (Ed.), Traumatic brain injury: Rehabilitation for everyday adaptive living. Hove: Lawrence Erlbaum Associates.

Rosser, A., \& Hodges, J.R. (1994). Initial letter and semantic category fluency in Alzheimer's disease, Huntington's disease, and progressive supranuclear palsy. Journal of Neurology, Neurosurgery and Psychiatry, 57, $1389-1394$.

Schmitter-Edgecombe, M. (1996). Effects of traumatic brain injury on cognitive performance: An attentional resource hypothesis in search of data. Journal of Head Trauma Rehabilitation, 11 (2), $17-30$

Suzman, S. (1996). Personal communication. Linguistics Department. Johannesburg: University of Witwatersrand.

van Ede, D.M. (1996). How to adapt a measuring instrument for use with various culture groups: A practical step-by-step introduction. South African Iournal of Higher Education, 10 (2), 153-160.

Vaughn-Cooke, F.B. (1986). Clinical principles for language intervention for language disorders among nonstandard speakers of English. In $\mathrm{O}$. Taylor (Ed.). Treatment of communication disorders in culturally and linguistically diverse populations. California: College-Hill Press.

von Fraunhofer, J.A. \& Murray, J.J. (1976). Statistics in medical, dental and biological studies. London: Tri-Med Books.

Watt, N., Penn, C. \& Jones, D. (1996). Speech-language evaluation of closed head injured subjects in South Africa: Cultural applicability and ecological validity of a test battery. The South African Journal of Communication Disorders, 43, 85-92. 